\title{
Assessment of the nutritional status of adolescent girls aged between 15 to 18 years studying in government high school in Raipur, Chhattisgarh, India
}

\author{
Phuljhele S. ${ }^{1}$, Dewangan S. ${ }^{2}$, A. $^{3 *}$ \\ DOI: https://doi.org/10.17511/ijpr.2021.i02.06
}

${ }^{1}$ Sharja Phuljhele, Professor and HOD, Department of Paediatrics, Pt. JNM Medical College, Raipur, Chhattisgarh, India.

2 Shashikant Dewangan, Assistant Professor, Department of Paediatrics, Pt. JNM Medical College, Raipur, Chhattisgarh, India.

3* Anu , Postgraduate, Department of Paediatrics, Pt. JNM Medical College, Raipur, Chhattisgarh, India.

Introduction: The prevalence of malnutrition among adolescent girls is high in India. Malnutrition has long term effects on the physical and mental health of adolescents. Objectives: To find out the prevalence of underweight, overweight and stunting and correlate with a dietary pattern, sociodemographic profile and prevalence of clinical anemia and signs of vitamin and mineral deficiency. Method: This is a community-based cross-sectional observational study conducted for 1 year (Jan 2019 - Dec 2019), including a total of 480 adolescent girls who were attending government high school. Observations and Result: 480 girls were interviewed. As per WHO nutritional measurement criteria, adolescent girls were classified as per their anthropometric criteria, $50.63 \%$ of girls were moderately stunted and $7.29 \%$ had severe stunting. $7.29 \%$ of girls were in the category of severe thinness, $36.04 \%$ had thinness and $9.37 \%$ were overweight. $28.12 \%$ had conjunctival pallor (anaemia), $4.80 \%$ had dental caries, $1.46 \%$ had vitamin B complex deficiency and $1.04 \%$ had signs of vitamin A deficiency. Conclusion: More than half of the (57.92\%) late adolescent school girls were stunted, $43.33 \%$ were having some form of thinness and $28.12 \%$ had clinical anaemia. Effective implementation of government programs such as the RKSK and Sabla Yojana program will be a paradigm shift from the existing clinic-based services to promotion and prevention and reaching adolescents in their environment, such as in schools, families and communities. Skills-based nutrition education for the family and effective infection control and routine health assessment of school-going girls should be done.

Keywords: Adolescent girls, Government high schools, Nutritional status

Corresponding Author

Anu , Postgraduate, Department of Paediatrics, Pt. JNM Medical College, Raipur, Chhattisgarh, India. Email: anu.krishna301@gmail.com

\section{How to Cite this Article}

Phuljhele S, Dewangan S, Anu. Assessment of the nutritional status of adolescent girls aged between 15 to 18 years studying in government high school in Raipur, Chhattisgarh, India. Pediatric Rev Int J Pediatr Res. 2021;8(2):100-108.

Available From

https://pediatrics.medresearch.in/index.php/ijpr/arti cle/view/671
To Browse

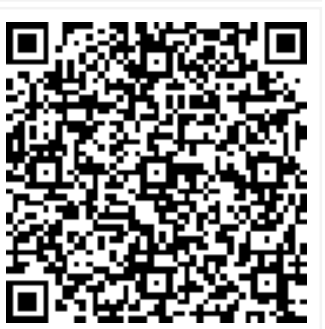

Manuscript Received 2021-04-05

Conflict of Interest No

Review Round 1
2021-04-15
Funding
Nil

C 2021 by Sharja Phuljhele, Shashikant Dewangan, Anu and Published by Siddharth Health Research and Social Welfare Society. This is an Open Access article licensed under a Creative Commons Attribution 4.0 International License https://creativecommons.org/licenses/by/4.0/ unported [CC BY 4.0]. 


\section{Introduction}

Adolescents are people aged between 10 to 19 years. More than 1.2 billion are adolescents worldwide [1]. About $21 \%$ of the Indian population is comprised of adolescents [2]. They require balanced nutrition comprising of macronutrients and micronutrients which helps in a rapid growth spurt and increased physical activity. The National Family Health Survey revealed that in the age group of 1519 years, about $41.9 \%$ of girls were thin while $4.2 \%$ of girls were overweight [3]. Thinness (low BMI-forage) is a common problem among adolescents in India. Many girls are also overweight and obese [4]. This ensues as a double burden of malnutrition which is due to nutritional transition [5]. Undernutrition leads to decreased immunity whereas overweight adolescents are predisposed to non-communicable diseases [6]. Assessment of nutritional status is valuable to predict efficient physical activity and healthy reproductive outcome. Nutritional status is the physiological state of an individual, which results from the relationship between multiple factors such as nutrient intake, requirement and body's ability to digest, absorb and use these nutrients and factors that affect the abovementioned factors. It is a total of an individual's anthropometric indices and factors that influence the dietary pattern of that individual. These include external factors such as food safety, cultural, social, economical factors and internal factors which include age, sex, nutrition, behaviour, physical activity and diseases of the person.

Chronic undernutrition leads to short stature in adolescents. It also causes reduced lean body mass and decreased muscular strength and physical capacity. Low literacy levels, poor socioeconomic status, poor environmental hygiene, poor dietary habits aggravate malnutrition. Undernutrition continues indefinitely across generations, particularly in girls. Puberty and menarche increase energy and nutrients demand leading to thinness, stunting and various micronutrient deficiencies [7]. Growth spurt, poor nutrition, menarche and poor dietary habits predispose an adolescent girl to anemia. Anemia limits growth and may further delays the onset of menarche, which in turn may later lead to cephalopelvic disproportion. Iron deficiency is the most common manifestation of malnutrition among adolescent girls. India has the highest prevalence of iron deficiency anemia among women, including adolescents [8].
Micronutrient deficiencies such as vitamin A, B complex, $\mathrm{C}$, iron, zinc and calcium deficiencies are common. Vitamin A deficiency causes dry conjunctiva and an impaired immune system. Vitamin B complex compounds anemia and leads to oral ulcers and angular stomatitis. Vitamin $C$ deficiency causes bleeding tendencies. Iron deficiency leads to anemia and poor motor and cognitive development [9].

Zinc deficiency impairs the immune system which causes infections, which further has deleterious effects on health. Calcium deficiency leads to poor growth and weak bones. Poor dietary patterns like snacking, skipping meals especially breakfast, irregular meal timings, fast food etc. are common among adolescents in the school-going age group. Poor eating habits and lifestyle leads to severe morbidities in later stages of life.

Socio-demographic factors and economic factors including adolescent's age, mother's age, parents' occupation and income, literacy level, dietary habits and cultural factors are associated with the nutritional status of adolescents [10]. This is mainly due to nutrition, epidemiologic, and sociodemographic transition across the world. Socioeconomic status affects the nutritional status of adolescents. The level of maternal education was found to be associated with the nutritional status of children. This implies that the ability of mothers to care for their children is high among literate mothers.

\section{Aim}

To assess the nutritional status of adolescent girls aged between 15 to 18 years studying at different government high schools in Raipur by using anthropometric measurements and clinical examination.

\section{Objectives}

Primary objective: To find out the prevalence of underweight, overweight and stunting.

Secondary objectives:

01. To correlate dietary patterns to the nutritional status of adolescent girls.

02. To correlate socio-demographic profile to the nutritional status of adolescent girls.

03. To find out the prevalence of clinical anemia and signs of vitamin and micronutrient deficiency. 


\section{Material and Method}

Type of study- It is a community-based crosssectional observational study.

Study setting- Different government high schools and higher secondary schools in the urban area of Raipur, Chhattisgarh, India.

Study period- Jan 2019-Dec 2019

Study population- A total of 480 adolescent girls who were aged between 15 to 18 years and attending government high and higher secondary schools in Raipur.

\section{Inclusion criteria-}

01. Girls attending government high schools and higher secondary school

02. Age group $15-18$ years

03. Girls studying in class IX-XII

\section{Exclusion criteria-}

01. Girls not consenting to participate

02 . Age group $<15$ years and $>18$ years

03. Girls studying in classes other than IX-XII

04. Girls with a known history of any hemoglobinopathies or dysmorphic features

05. Girls having any chronic disease affecting nutrition.

Methodology/ data collection-

All the selected adolescent girls were personally interviewed with the help of a questionnaire regarding age, type of family, dietary pattern and socioeconomic status. The anthropometric measurements of the selected adolescent girls were measured by following standard procedures. Anthropometric measurements like height $(\mathrm{cm})$, weight $(\mathrm{kg})$, body mass index $(\mathrm{kg} / \mathrm{m} 2)$ were recorded and general and systemic examination was done.

Following schedules were filled during the study period-

Schedule A Data collection format of Anthropometric measurement

Schedule B Interview questionnaire of study subjects

Schedule C Clinical Examination form for study samples

\section{Major variables-}

01. Weight

02. Height

03. Body mass index

\section{Outcome variables-}

01. Proportion of adolescent girls classified as underweight or overweight/obese

02. Proportion of girls with moderate or severe stunting

03. Proportion of clinically anemic girls.

04. Proportion of adolescent girls with different vitamin or mineral deficiency.

\section{Confounding factors-}

01. Socio-economic status

02. Parental education

03. Parental occupation

04. Menstrual history

05. Food habit.

Data entry and analysis- Data entry was done in Excel and analysis was done using SPSS 20.0 and WHO Anthroplus software. Wherever possible, percentage, Chi-square test and logistic regression were applied. P-value $<0.05$ was considered as statistically significant.

Ethical issues- Informed consent was taken from mothers of all the study participants and ethical issues were considered.

\section{Results}

- 120 study samples were taken from each age group.

- The mean weight of adolescent girls was $42.08 \pm 7.17 \mathrm{~kg}$ and height was $146.87 \pm 3.84 \mathrm{~cm}$ in 15 year age group. Mean weight was $41.66 \pm 7.50 \mathrm{~kg}$ and height was $146.75 \pm 3.75 \mathrm{~cm}$ in 16 years age group. Mean weight was $41.07 \pm 6.33 \mathrm{~kg}$ and height was $147.54 \pm 3.74 \mathrm{~cm}$ in 17 years age group. Mean weight was $41.77 \pm 7.80$ and height was $147.66 \pm 3.64$ in the 18 years age group. The mean weight $(\mathrm{kg})$ of adolescent girls was $41.64 \pm 7.26$, mean height $(\mathrm{cm})$ was $147.20 \pm 3.75$ and mean BMI $(\mathrm{Kg} / \mathrm{M} 2)$ was $19.25 \pm 3.44$.

- As per WHO criteria for Height for Age (H/A) which measure stunting in girls, $42.08 \%$ were normal, $50.62 \%$ were moderately stunted and 
$7.30 \%$ of girls were severely stunted.

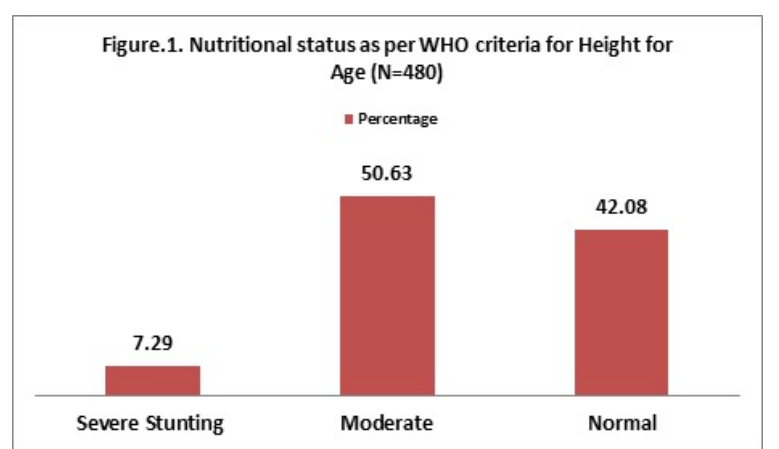

- As per WHO criteria for Body Mass Index (BMI, $47.30 \%$ were normal, $9.40 \%$ were overweight, $36.04 \%$ were thin and $7.30 \%$ girls were severely thin.

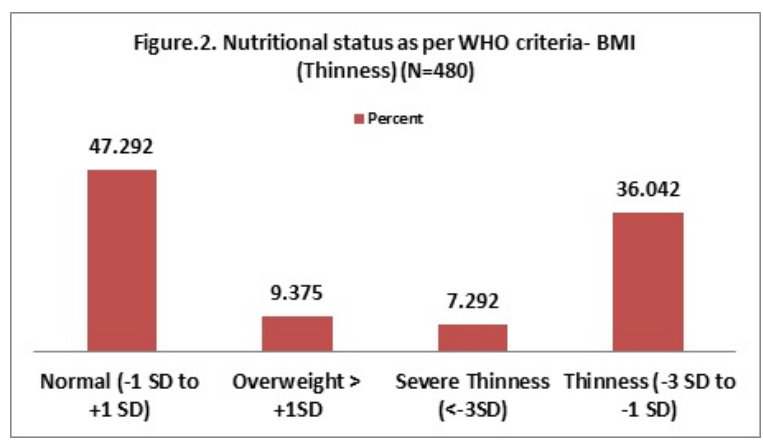

Table 1: Distribution of Major morbidity conditions in study subjects

\begin{tabular}{|l|l|l|}
\hline \multicolumn{1}{|c|}{ Disease } & Frequency & Percentage \\
\hline Anemia (Conjunctivital Pallor) & 135 & 28.12 \\
\hline Dental Carries & 23 & 4.80 \\
\hline Vitamin B Complex deficiency & 7 & 1.46 \\
\hline Vitamin A deficiency (Bitot's spot) & 5 & 1.04 \\
\hline
\end{tabular}

- Table 1 shows the prevalence of clinical anemia and signs of vitamin and mineral deficiency among study participants. $28.12 \%$ had clinical pallor (anemia), 4.80\% had dental carries, $1.46 \%$ had signs of vitamin B complex deficiency and $1.04 \%$ had signs of vitamin A deficiency.

- A multivariate logistic regression statistical tool was used to understand the determinants of malnutrition in study subjects. Severely stunted and moderate stunted were considered 'stunted' as one category and rest were considered 'normal' as another category. Then other variables i.e. age of children, educational class, Religion, Parents education, Parents occupation, socio-economic class, type of family, immunization status and menstrual history were taken as the independent variable.
Table 2: Multivariate analysis for determinants of stunting in adolescent girls from 15 to 18 years old:

\begin{tabular}{|c|c|c|c|c|c|}
\hline Variables & $\begin{array}{l}\text { Stunting } \\
\qquad(\%)\end{array}$ & $\begin{array}{l}\text { Odds } \\
\text { Ratio }\end{array}$ & $\begin{array}{l}\text { P- } \\
\text { value }\end{array}$ & \multicolumn{2}{|c|}{$\begin{array}{c}{[95 \%} \\
\text { Conf.Interval }\end{array}$} \\
\hline \multicolumn{6}{|l|}{ Age in years } \\
\hline 15 year & 55 & Ref. & & & \\
\hline 16 year & 58.3 & 0.876 & 0.649 & 0.495 & 1.551 \\
\hline 17 year & 60 & 1.053 & 0.858 & 0.595 & 1.864 \\
\hline 18 year & 58.3 & 1.062 & 0.842 & 0.588 & 1.919 \\
\hline \multicolumn{6}{|l|}{ Religion } \\
\hline Hindu & 59.4 & Ref. & & & \\
\hline Muslim & 57.7 & 0.840 & 0.547 & 0.475 & 1.483 \\
\hline Christian & 36 & 0.202 & 0.004 & 0.069 & 0.595 \\
\hline \multicolumn{6}{|c|}{ Mother's education } \\
\hline Illiterate & 57.1 & Ref. & & & \\
\hline Primary & 63.5 & 1.863 & 0.194 & 0.728 & 4.767 \\
\hline High school & 43.8 & 1.319 & 0.754 & 0.233 & 7.461 \\
\hline $\begin{array}{l}\text { Higher } \\
\text { Secondary }\end{array}$ & 57.1 & 1.194 & 0.714 & 0.463 & 3.080 \\
\hline \multicolumn{6}{|c|}{ Father's education } \\
\hline Illiterate & 58.5 & Ref. & & & \\
\hline Primary & $57 . .4$ & 0.913 & 0.868 & 0.312 & 2.672 \\
\hline Middle & 75 & 1.565 & 0.617 & 0.270 & 9.074 \\
\hline High school & 33.3 & 0.309 & 0.342 & 0.027 & 3.482 \\
\hline $\begin{array}{l}\text { Higher } \\
\text { Secondary }\end{array}$ & 56.6 & 0.977 & 0.965 & 0.337 & 2.832 \\
\hline Graduate & 61.5 & 1.400 & 0.582 & 0.423 & 4.631 \\
\hline \multicolumn{6}{|c|}{ Father's occupation } \\
\hline Daily wages & 64.2 & Ref. & & & \\
\hline Job & 55.5 & 0.337 & 0.025 & 0.130 & 0.872 \\
\hline Self business & 55.5 & 0.519 & 0.142 & 0.216 & 1.245 \\
\hline \multicolumn{6}{|c|}{ Mother's occupation } \\
\hline Daily wages & 59 & Ref. & & & \\
\hline House wives & 57.8 & 1.105 & 0.835 & 0.432 & 2.828 \\
\hline \multicolumn{6}{|c|}{ Socio-economic status } \\
\hline Lower & 100 & Ref. & & & \\
\hline Lower middle & 56.5 & 0.937 & 0.921 & 0.256 & 3.425 \\
\hline Upper lower & 57.1 & 0.821 & 0.795 & 0.187 & 3.616 \\
\hline Upper middle & 60.9 & 1.000 & & & \\
\hline
\end{tabular}

Table 3: multivariate analysis for determinants of stunting in adolescent girls from 15 to 18 years old(continued):

\begin{tabular}{|l|l|l|l|l|l|}
\hline \multicolumn{5}{|l|}{ Type of family } & \multicolumn{5}{|l|}{} & Ref. & & & \\
\hline Joint & 58 & 0.999 & 0.997 & 0.647 & 1.544 \\
\hline Nuclear & 57.9 & 0.9 & & \\
\hline Environmental hygiene & 59.2 & Ref. & & 0.447 & 2.669 \\
\hline Good & 56.9 & 1.093 & 0.846 & 0.177 & 2.816 \\
\hline Fair & 60.8 & 0.706 & 0.622 & 0.16 \\
\hline Poor
\end{tabular}




\begin{tabular}{|l|l|l|l|l|l|}
\hline Immunization status & 58.5 & Ref. & & & \\
\hline Complete & 51.2 & 0.738 & 0.425 & 0.350 & 1.556 \\
\hline Incomplete & 59 & Ref. & & & \\
\hline Menstrual history & 52.1 & 0.675 & 0.157 & 0.392 & 1.163 \\
\hline Regular & 60.9 & Ref. & & & \\
\hline Irregular & 57.8 & 1.065 & 0.894 & 0.423 & 2.680 \\
\hline Teeth & 52.3 & Ref. & & & \\
\hline Carries & 63.5 & 1.677 & 0.010 & 1.133 & 2.483 \\
\hline Normal & 54.6 & Ref. & & & \\
\hline Diet & 62.5 & 1.486 & 0.053 & 0.995 & 2.220 \\
\hline Vegetarian & Non Vegetarian & & & \\
\hline Pattern of diet & \multicolumn{7}{|l|}{} \\
\hline Regular & Irregular
\end{tabular}

Table. 2 and 3. shows that 17 and 18 years old girls have more chance of being stunted whereas 16 years old has less chance ( $O R=.876, P=0.876$ ) of being stunted as compare to 15 years old; though this difference is not statistically significant. As compared to Hindu girl, Muslim and Christian girl has less chance of stunting. Parents' education does not have a significant impact on the height of adolescent girls. Girls who had educated mothers had more chance of being stunted.

Girls whose fathers were educated till middle school has 1.56 times more chance (OR-1.565, $p=0.617$ ) and those who were graduate has 1.4 times more chance (OR-1.4, $\mathrm{p}=0.582$ ) of stunting as compared to girls having illiterate fathers. Girls having fathers who had a job had less chance of stunting (OR0.337, $P=0.025$ ) as compared to girls having fathers who were daily wagers.

Girls having mothers who were housewives had 1.105 times more chance (OR-1.105, $\mathrm{p}=0.142$ ) of stunting as compared to girls having mothers who were on daily wages. Type of family does not have a significant impact on the height of a girl child. Girls with lower socio-economic status have more chance of stunting as compared to the lower-middle and upper lower class.

Similarly environmental hygiene, menstrual history, immunization status and dental carries do not have a significant impact on the stunting status of adolescent girls. Adolescent girls who were nonvegetarian had more chance of being stunted (OR1.677, $P=0.01$ ) as compared to vegetarian girls. Adolescent girls who had irregular diet had more chance of being stunted (OR-1.486, $\mathrm{P}=0.05$ ) as compared to girls having regular diet.
Table 4: Multivariate analysis for determinants of thinness in adolescent girls from 15 to 18 years old girls

\begin{tabular}{|c|c|c|c|c|c|}
\hline Variables & $\begin{array}{c}\text { Thinness } \\
(\%)\end{array}$ & $\begin{array}{l}\text { Odds } \\
\text { Ratio }\end{array}$ & $\begin{array}{c}P \\
\text { value }\end{array}$ & \multicolumn{2}{|c|}{$\begin{array}{c}{[95 \%} \\
\text { Conf.Interval] }\end{array}$} \\
\hline \multicolumn{6}{|l|}{ Age in years } \\
\hline 15 year & 35 & Ref. & & & \\
\hline 16 year & 41.7 & 1.488 & 0.200 & 0.810 & 2.733 \\
\hline 17 year & 50.8 & 2.470 & 0.003 & 1.359 & 4.490 \\
\hline 18 year & 45.8 & 1.950 & 0.035 & 1.047 & 3.630 \\
\hline \multicolumn{6}{|l|}{ Religion } \\
\hline Hindu & 36.2 & Ref. & & & \\
\hline Muslim & 70.4 & 3.810 & 0.000 & 2.089 & 6.946 \\
\hline Christian & 76 & 5.216 & 0.002 & 1.858 & 14.642 \\
\hline \multicolumn{6}{|c|}{ Mother's education } \\
\hline Illiterate & 53.2 & Ref. & & & \\
\hline Primary & 34.6 & 0.927 & 0.880 & 0.349 & 2.467 \\
\hline Middle & 100 & 1.000 & & & \\
\hline High school & 62.5 & 3.260 & 0.202 & 0.530 & 20.055 \\
\hline $\begin{array}{l}\text { Higher } \\
\text { Secondary }\end{array}$ & 42.6 & 1.558 & 0.381 & 0.578 & 4.199 \\
\hline \multicolumn{6}{|c|}{ Father's education } \\
\hline Illiterate & 56.9 & Ref. & & & \\
\hline Primary & 61.7 & 1.209 & 0.737 & 0.399 & 3.661 \\
\hline Middle & 50 & 0.778 & 0.763 & 0.151 & 3.999 \\
\hline High school & 66.7 & 1.481 & 0.752 & 0.130 & 16.852 \\
\hline $\begin{array}{l}\text { Higher } \\
\text { Secondary }\end{array}$ & 39.5 & 0.596 & 0.359 & 0.197 & 1.804 \\
\hline Graduate & 31.9 & 0.576 & 0.388 & 0.165 & 2.014 \\
\hline \multicolumn{6}{|c|}{ Father's occupation } \\
\hline Daily wages & 56 & Ref. & & & \\
\hline Job & 34.9 & 0.623 & 0.316 & 0.247 & 1.571 \\
\hline Self business & 43.8 & 0.653 & 0.319 & 0.282 & 1.510 \\
\hline \multicolumn{6}{|c|}{ Mother's occupation } \\
\hline Daily wages & 69.2 & Ref. & & & \\
\hline House wives & 41 & 0.554 & 0.230 & 0.211 & 1.452 \\
\hline \multicolumn{6}{|c|}{ Socio-economic status } \\
\hline Lower & 88.9 & Ref. & & & \\
\hline Lower middle & 37.3 & 0.304 & 0.327 & 0.028 & 3.289 \\
\hline Upper lower & 46.3 & 0.292 & 0.295 & 0.029 & 2.921 \\
\hline Upper middle & 30.4 & 0.287 & 0.385 & 0.017 & 4.787 \\
\hline
\end{tabular}

Table 5: Multivariate analysis for determinants of thinness in adolescent girls from 15 to 18 years old (continued):

\begin{tabular}{|l|l|l|l|l|l|}
\hline \multicolumn{5}{|l|}{ Type of family } \\
\hline Joint & 38.5 & Ref. & & & \\
\hline Nuclear & 45.4 & 1.137 & 0.577 & 0.724 & 1.787 \\
\hline Environmental hygiene & 32.7 & Ref. & & & \\
\hline Good & 40.4 & 1.203 & 0.713 & 0.449 & 3.228 \\
\hline Fair & & & & \\
\hline
\end{tabular}




\begin{tabular}{|l|l|l|l|l|l|l|}
\hline Poor & 58.8 & 1.299 & 0.683 & 0.370 & 4.564 \\
\hline Immunization status & 44.2 & Ref. & & & \\
\hline Complete & 34.1 & 0.428 & 0.036 & 0.194 & 0.947 \\
\hline Incomplete & 42 & Ref. & & & \\
\hline Menstrual history & 50.7 & 1.349 & 0.301 & 0.765 & 2.377 \\
\hline Regular & 43.5 & Ref. & & & \\
\hline Irregular & 43.3 & 0.937 & 0.895 & 0.357 & 2.464 \\
\hline Teeth & 44.4 & Ref. & & & \\
\hline Carries & 42.3 & 0.919 & 0.682 & 0.613 & 1.376 \\
\hline Normal & 43.2 & Ref. & & & \\
\hline Diet & 43.5 & 0.923 & 0.702 & 0.612 & 1.391 \\
\hline Vegetarian & Non Vegetarian &
\end{tabular}

Table.4 and 5 . shows that 17 years old girls (OR2.47, $\mathrm{P}=0.003), 18$ years (OR-1.95, $\mathrm{P}=0.035)$ and 16 years $(P=0.20)$ have more chance of being thin as compared to 15 years old girls. As compared to Hindu girl, Muslim and Christian girls have a significantly more chance of being thin. Parents' education does not have a significant impact on the BMI of adolescent girls.

Girls having mothers who are educated till high school (OR-3.260, $p=0.202$ ) and who were graduate (OR-1.55, $p=0.381$ ) have more chance of thinness as compared to girls with illiterate mothers. Girls having fathers who do job and self business has less chance of thinness as compared to girls having fathers who are daily wagers. Girls having mothers who are housewives have less chance (OR-0.554, $p=0.230$ ) of thinness as compared to girls having mothers who are daily wagers.

Type of family does not have a significant impact on the BMI of girls. Girls with lower socio-economic status have more chance of thinness as compared to the lower-middle and upper lower class. Environmental hygiene, menstrual history, immunization status, dental caries and diet do not have a significant impact on the BMI of adolescent girls.

\section{Discussion}

This study was conducted in government high schools of the state capital city, Raipur. 480 schoolgirls from 15 to 18 years of age group were assessed for their nutritional status. Socio-economic determinants were also assessed among study subjects.
In the present study, religion-wise analysis of nutritional status showed that $59.37 \%$ of Hindu girls were stunted as compared to $57.75 \%$ of Muslim girls and the association between underweight and religion was statistically significant. $36.20 \%$ of Hindu girls were thin as compared to $70.42 \%$ in Muslim girls which was statistically significant. As compared to Hindu girls, Muslim girls have more chance (OR- 3.81, $P=0.000$ ) of being thin. Rani $D$ et al (2018) in a similar study assessed the nutritional status of adolescent girls in an urban slum of Varanasi.

They reported that $60.4 \%$ of Hindu girls were thin as compared to $57.1 \%$ of Muslim girls. Though unlike our study, the association was statistically not significant [11]. Among girls having educated mothers, $58.06 \%$ of girl children were stunted as compared to $57.14 \%$ of girls having illiterate mothers. Among girls having educated mothers, $41 \%$ of girls were thin as compared to $53.24 \%$ of illiterate mothers. Among girls having educated fathers, $41.20 \%$ were thin as compared to $56.92 \%$ girls having illiterate fathers.

Girls having mothers who are educated till high school (OR-3.260, $p=0.202$ ) and who were graduate (OR-1.55, $p=0.381$ ) have more chance of being thin as compared to girls having illiterate mothers. The Association between parental education and the nutritional status of their children was statistically significant. A similar study by Singh K S et al (2014) in Makhinagarkhalapar block which is the field practice area of Muzaffarnagar Medical College, Muzaffarnagar (UP) reported that illiterate mothers had $50 \%$ girls whose BMI was $<18.5$ and who were educated had $19 \%$ girls whose BMI was $<18.5$ whereas illiterate fathers had girls whose BMI was $<18.5$ and who were educated had $28.72 \%$ girls whose BMI was < 18.5 [12].

In the present study, girls having fathers on daily wages had a high prevalence of thinness (55.97\%) as compared to girls having fathers who had jobs (34.93\%) and self business (43.80\%). Similarly girls having mothers who were on daily wages had more prevalence of thinness (69.23\%) as compared to girls having mothers who were housewives (41.04\%). The Association between parental occupation and the nutritional status of their children was statistically significant. Girls having fathers who had a job had less chance of thinness (OR-0.623, $\mathrm{P}=0.316$ ) as compared to girls having fathers who were on daily wages. 
Girls having mothers who are housewives has significantly less chance (OR-0.554, $p=0.230$ ) of thinness as compared to girls having mothers who were on daily wages. Raikwar R and Sharma K.K.N. (2018) in Sagar, Madhya Pradesh reported that it is apparent that a high prevalence of severe malnutrition is found in girls whose fathers were unemployed $(16.7 \%)$ as compared to other professions as daily wages and farmers. They revealed that a high prevalence of malnutrition is found in those adolescent girls whose mothers are labourer $(5.0 \%)$, housewives (3\%) and bidi worker (25\%).

There is a positive significant correlation found between father's occupation, mother's occupation, and Body Mass Index $(p<0.05)$ [13]. In the present study, the upper lower class has more prevalence (46.34\%) of thinness in girls as compared to the lower middle class (37.27\%) and upper-middle class (30.43\%) whereas the Upper middle class $(60.87 \%)$ has more prevalence of stunting as compared to the upper-lower class (57.14\%) and lower middle class (56.54\%). The Association between SES status and nutritional status of their children was statistically significant.

Nair A et al (2017) conducted a study to assess the nutritional status of adolescent girls during January 2015 to June 2015 in 10 villages included under the Primary Health Centre area of a district in Maharashtra reported that as per modified BG Prasad socioeconomic scale, SEC-I had $33.33 \%$ stunting, SEC-II had $40.91 \%$, SEC-III had $42.22 \%$, SEC-IV had $47.17 \%$ and SEC-V had $51.84 \%$ adolescent girls who were stunted. Also SEC-I had $33.33 \%$, SEC-II had $22.73 \%$, SEC-III had $26.67 \%$, SEC-IV had $13.58 \%$ and SEC-V had $22.45 \%$ adolescent girls who were thin [14].

In the present study, adolescent girls from the nuclear family $(45.4 \%)$ have more prevalence of thinness as compared to joint families (38.46\%). Among girls who lived in houses with poor environmental hygiene, $58.7 \%$ of girls were thin. Among girls who lived in houses with fair environmental hygiene, $40.41 \%$ of girls were thin. Among girls who lived in houses with good environmental hygiene, $32.6 \%$ were thin. There was a statistically significant association between environmental hygiene and the nutritional status of adolescent girls.

A similar study by Chandrashekarappa SM et al (2016) in $n$ the city of Mysore under JSS
Mahavidyapeetha reported that $64 \%$ of adolescent girls belonging to a nuclear family were thin as compared to $36.5 \%$ of girls belonging to joint families and it was statistically not significant [15]. Rani D et al (2018) did Assessment of Nutritional Status of Teenage Adolescent Girls in Urban Slum of Varanasi and reported that $53.9 \%$ of adolescent girls were undernourished in a joint family as compared to $62 \%$ in the nuclear family [11].

In the present study, the mean weight $(\mathrm{kg})$ of adolescent girls was 41.64 77.26, mean height $(\mathrm{cm})$ was $147.20 \pm 3.75$ and mean BMI $(\mathrm{Kg} / \mathrm{m} 2)$ was $19.25 \pm 3.44$. The maximum prevalence of thinness $(50.8 \%)$ was in 17 year age group followed by $47.5 \%$ in 15 years, $45 \%$ in 16 year age group and $43.3 \%$ in 18 years age group. A similar study by Chandrashekarappa SM et al (2016) in Mysuru reported that a maximum of $44.2 \%$ thinness was seen in 16 years age group and followed by $32.3 \%$ in 17 years and $32.7 \%$ in 18 years age group [15].

As per WHO criteria for Height for Age (H/A), which measure the level of stunting in girls, $50.63 \%$ were moderately stunted and $7.29 \%$ of girls were severely stunted. As per WHO criteria for Body Mass Index (BMI), $7.29 \%$ of girls were severely thin, $36.04 \%$ were thin and $9.37 \%$ were overweight. Dambhare DG et al (2010) did a similar study by Wardha among school-going adolescents. They reported that $27.5 \%$ were stunted [16]. Sachan B et al (2012) in Lucknow did a similar study on school-going adolescent girls. The overall prevalence of thinness was found to be $17.0 \%$ and $11.4 \%$ among urban and rural girls respectively [17].

The present study showed that $28.12 \%$ had conjunctival pallor (anemia), 4.80\% had dental carries, $1.46 \%$ had Vitamin B complex deficiency and $1.04 \%$ had Vitamin A deficiency (Bitot's spot). In a similar study DG Dambhare et al (2010) in Wardha among School going Adolescent girls reported that $38.89 \%$ had anaemia, $35.34 \%$ had dental caries, $6.9 \%$ adolescents had skin problems, and $2.59 \%$ had wax in the ear [18]. KM Susmitha et al (2012) in Nellore, A.P. study on Morbidity pattern among the adolescent girls residing in six social welfare hostels for scheduled caste students in Nellore. They reported the major prevalent morbid conditions among girls were pediculosis $83.21 \%$, dysmenorrhea $43.6 \%$ dental caries $28.04 \%$ and skin disorders $26.4 \%$ [18]. 


\section{Conclusion}

The present study was conducted among high school girls from government schools in Raipur city of Chhattisgarh state to evaluate their nutritional status and morbidity pattern. More than half of them $(57.92 \%)$ late adolescent school girls were stunted, $43.33 \%$ were having some form of thinness and $28.12 \%$ had clinical anemia. As a preventive strategy, there is a need to apply health and nutritional education program for inculcating healthy lifestyles. To ensure holistic development of adolescent GoI launched Rashtriya Kishor Swasthya Karyakram (RKSK) in 2014.

The programme expands the scope of adolescent health programming in India - from being limited to sexual and reproductive health, to nutrition, injuries and violence (including gender-based violence), non-communicable diseases, mental health and substance misuse. The Chhattisgarh government with the Women and Child development department started the Sabla Yojana programme targets adolescent girls between 11-18 years. Services provided include Nutritional supplement, iron and folic acid (IFA) supplementation, biannual deworming, medical examination and education on topics including nutrition, hygiene, the legal age of marriage, and the benefits of delaying childbearing. Nutrition education can have a significant effect in promoting healthy eating habits, and schools can contribute to reducing nutrition-related problems by integrating nutrition interventions into a comprehensive school health program.

\section{What does this study add to existing knowledge?}

Effective implementation of these programs will be a paradigm shift from the existing clinic-based services to promotion and prevention and reaching adolescents in their environment, such as in schools, families and communities. Skills-based nutrition education for the family and effective infection control and routine health assessment of school-going girls should be done.

\section{Author's contribution}

Dr. Sharja Phuljhele: concept and study design, Dr. Shashikant Dewangan: manuscript writing, Dr. Anu: manuscript writing and statistical analysis

\section{Reference}

01. Cappa C, Wardlaw T, Langevin-Falcon C, Diers J. Progress for children- a report card on adolescents. Lancet. 2012 Jun 23;379(9834)2323-5.

doi: $10.1016 / \mathrm{S} 0140-6736(12) 60531-5 \quad$ [Crossref]

02. Handbook, Strategy. "Rashtriya Kishor Swasthya Karyakram. " Adolescent Health Division Ministry of Health and Family Welfare Government of India. 2014.

[Crossref]

03. International Institute for Population Sciences, and Macro International. National Family Health Survey (NFHS-4), 2015-16- India. MumbaiIIPS. Vol $1 ; 2016$. [Article] [Crossref]

04. Sharma J, Mondal N. Prevalence of Double Nutrition Burden Among Adolescent Girls of Assam, Northeast India. Journal of Nepal Paediatric Society. 2014;34(2).

[Crossref]

05. Hasan M, Sutradhar I, Shahabuddin A, Sarker M. Double Burden of Malnutrition among Bangladeshi Women- A Literature Review. Cureus. 2017 Dec 26;9(12)e1986.

doi: $10.7759 /$ cureus.1986 [Crossref]

06. Gupta A, Sharma D, Thakur D, Thakur A, Mazta SR. Prevalence and predictors of the dual burden of malnutrition among adolescents in North India. Saudi J Obesity. 2014;2;63-79.

[Crossref]

07. Human energy requirements, Report of a Joint FAO/WHO/UNU Expert Consultation. Food and nutrition technical report series. Rome, 17-24 Oct2001. Available at:

[Article] [Crossref]

08. Dallman PR, Siimes MA, Stekel A. Iron deficiency in infancy and childhood. Am J Clin Nutr. 1980 Jan;33(1)86-118.

doi: $10.1093 /$ ajen/33.1.86 [Crossref]

09. Debnath S, N Mondal, J Sen. "Socio-economic and demographic correlates of stunting and thinness among rural school-going children (aged 5-12 years) of North Bengal, Eastern India. " J Life Sci. 2018;10(1)14-31.

[Crossref] 
10. Divya Rani, Jitendra Kumar Singh, Mona Srivastava, Pragya Verma, Deepali Srivastava, S $P$ Singh. Assessment of Nutritional Status of Teenage Adolescent Girls in Urban Slum of Varanasi. International Journal of Current Research and Review Research. 2018.

DOI: [Article] [Crossref]

11. Singh S K, Garg G, Davey S, Raghav S K, Muzammil K, Singh J V. Impact of educational status of parents on nutritional status of adolescent girls-a cross sectional study. National Journal of Community Medicine. 2014;5(3)266269.

[Crossref]

12. Raikwar $\mathrm{R}$, Sharma KKN. Influence of parental occupation on nutritional status of adolescent girls of other backward class (OBCs), Sagar district, Madhya Pradesh. International Journal of Movement Education and Social Science. 2018 Oct; $7(2)$.

[Crossref]

13. Nair A, Doibale M K, Kuril B M, VK D. Study of nutritional status of adolescent girls in a rural area of a district of Maharashtra. Inter J Commu Med Pub Health. 2017;4(12)4617.

[Crossref]
14. Chandrashekarappa S M, Ramakrishnaiah N M M, Manjunath R. Nutritional status in adolescent girls: Attempt to determine its prevalence and its association with sociodemographic variables. Family Medicine and Community Health. 2018;6(4)184-190.

[Crossref]

15. Dambhare D G, Bharambe M S, Mehendale A M, Garg B S. Nutritional status and morbidity among school going adolescents in Wardha, a Peri-Urban area. Online Journal of Health and Allied Sciences. 2010;9(2).

[Crossref]

16. Sachan B, Idris M Z, Jain S, Kumari R, Singh A. Nutritional status of school going adolescent girls in Lucknow District. Journal of Medical Nutrition and Nutraceuticals. 2012;1(2)101. [Crossref]

17. KM Susmitha, Jyothi C, Prabakaran J. Morbidity pattern among the adolescent girls- A study in the social welfare hostels for scheduled castes, Nellore city, AP, India. Nat J Res Com Med. 2012;1(1)01-60.

[Crossref] 